Jurnal Ekonomi dan Bisnis, Vol. 8 No. 2 September 2021

$$
\begin{array}{ll}
\text { P - ISSN } & : \mathbf{2 5 0 3 - 4 4 1 3} \\
\text { E - ISSN } & : \mathbf{2 6 5 4 - 5 8 3 7} \text {, Hal 101-107 }
\end{array}
$$

\title{
PENGARUH EVENT PUTERI INDONESIA DAN ELVIRA DEVINAMIRA TERHADAP PERSEPSI MASYARAKAT ATAS WANITA INDONESIA \\ Oleh :
}

Abdy Azwar Sahi

London School Public Relation

Email ; abdy.azwar@gmail.com

Agatha Corintias Winarti

London School Public Relation

Email ; agathacorintias@gmail.com

Yudha Satrio Leksono

London School Public Relation

Email:leksonosatrioyudha@gmail.com

Article Info

Article History:

Received 30 March - 2021

Accepted 14 July - 2021

Available Online 25 Sept 2021

\section{Keyword:}

Event Marketing, Puteri

Indonesia, Society

Perception, Elvira

Devinamira

\section{PENDAHULUAN}

Aktifitas Public Relations tidak hanya sekedar menjaga citra perusahaan atau sebuah organisasi, namun juga sebagai jembatan antara masyarakat dan perusahaan dalam mengedukasi sesuai dengan tujuan dari perusahaan itu sendiri. Tanpa adanya public relations yang efektif, organisasi cenderung menjadi tidak peka terhadap perubahan yang terjadi disekitarnya dan pertumbuhan justru menuju kearah yang tidak diinginkan. Selain selalu memberikan informasi terbaru kepada media, public relations juga membantu organisasi dalam membentuk dan memelihara relasi yang saling menguntungkan hingga menunjukkan sebuah fungsi manajemen yang 
berpengaruh pada masyarakat luas (John P. Simandjuntak, 2003, pp. 17-19).

Kemudian kegiatan lain dari Public Relations adalah mampu memberikan pemahaman kepada publik dan meraih simpati masyarakat terhadap suatu jasa atau produk melalui tulisan seperti artikel dan press release. Selanjutnya kegiatan Public Relations juga tidak lepas dari PR Campaign atau kampanye PR, Dimana dalam menjalankan kampanye tersebut kegiatan didalam nya mencakup: publikasi, pemberdayaan masyarakat, promosi di media, tulisan hingga penyelenggaraan Event (Butterick, 2012, p. 12).

Penyelenggaraan Event telah berkembang sesuai dengan keinginan konsumen misalnya Event yang bersifat hiburan, edukasi, iklan produk, pencarian bakat, hingga kontes kecantikan atau beauty pageant. Beauty pageant atau kontes kecantikan yang kian marak saat ini hadir ditengah kehidupan sosial masyarakat, adalah sebuah kompetisi yang mengikutsertakan peserta wanita dengan gambaran umum seperti menggunakan gaun yang mewah serta menampilkan keindahan fisik diatas panggung yang megah.

Miss World, Miss Universe, Miss International, dan Miss Earth adalah 4 ajang beauty pageant bergengsi tingkat dunia yang sangat dinanti para penggemar beauty pageant setiap tahun nya. Dimana kontes ini memiliki usia yang tidak tergolong muda lagi. Sebut saja Miss World, beauty pageant ini didirikian oleh Eric Morley pada tahun 1951 di Inggris. Pada awal pembentukannya Miss World dimulai sebagai Festival kontes bikini untuk mengenalkan ke masyarakat Inggris akan jenis pakaian renang terbaru saat itu, namun para awak media menyebutnya sebagai "Miss World".

Beauty pageant ini memiliki motto berbunyi "Beauty With a Purpose" atau yang memiliki arti "Kecantikan Dengan Tujuan" dimana para peserta dituntut untuk tidak hanya cantik namun dapat memberikan dampak positif melalui program kerja atau kegiatan yang dibuat untuk membantu dan mengembangkan potensi suatu daerah seperti kegiatan amal, pendidikan, kesehatan, dan masih banyak lagi. Kemudian setahun setelah kehadiran Miss World, di Amerika Serikat pada tahun 1952 juga lahir beauty pageant yang tidak kalah bergengsi, yaitu Miss Universe.

Menyadari akan segala potensi alam dan sumber daya yang melimpah, Indonesia pun turut serta dalam mengambil andil dibidang beauty pageant. Salah satu ajang pemilihan beauty pageant bergengsi di Indonesia adalah Puteri Indonesia. Pemilihan Puteri Indonesia di prakarsai oleh ibu Mooryati Soedibyo dibawah naungan Yayasan Puteri Indonesia yang dimulai pada tahun 1992 dan disponsori oleh perusahaan kosmetik Mustika Ratu. Pemilihan Puteri Indonesia ini adalah wadah bagi wanita Indonesia dalam menciptakan karakter yang berbudaya dan mencerminkan sikap seorang wanita yang anggun sesuai dengan kepribadian bangsa. Bukan hanya itu para pemenang Puteri Indonesia juga akan menjadi duta bangsa yang ikut serta mempromosikan dan memperkenalkan segala aspek budaya dan wisata yang ada di Indonesia ke dunia luar. Para peserta Puteri Indonesia adalah perempuan Warga Negara Indonesia yang berasal dari 33 provinsi di Indonesia berusia 1825 tahun, belum menikah, mahasiswi atau karyawati dengan tinggi badan minimum $168 \mathrm{~cm}$.

Elvira Danamira adalah pemenang Puteri Indonesia tahun 2014. Elvira berhasil menyisihkan 36 peserta lainnya dan merebut gelar Puteri Indonesia 2014 yang ditayangkan secara live di stasiun TV Indosiar pada tanggal 29 January 2014 di Plenary Hall Jakarta Convention Center. Elvira adalah kontestan perwakilan dari Jawa Timur yang juga merupakan mahasiswa hukum di Universitas Airlangga. Gadis kelahiran Surabaya 28 Juni 1993 ini pernah menjadi wakil Indonesia di Harvard Model United Nation 2012. Elvira juga pernah menyandang gelar sebagai duta wisata Surabaya yakni Wakil 1 Ning Surabaya 2012. Dalam masa jabatannya sebagai Puteri Indonesia 2014 Elvira aktif dalam kegiatan sosial, pendidikan, dan promosi kebudayaan hingga pariwisata Indonesia.

Seperti yang dikutip dari hasil wawancara bersama majalah Star Glam, Elvira mendonasikan jam tangan nya dan dilelang dengan harga 600 juta rupiah kemudian hasil dari pelelangan tersebut disumbangkannya ke korban letusan Gunung Kelud beberapa waktu silam. Tidak hanya menyumbangkan dana, tapi Elvira turut terjun langsung dan memberikan semangat pada korban bencana letusan Gunung Kelud.

Namun dalam masa tugas nya sebagai Putri Indonesia Elvira sempat diterpa kabar miring. Dimana ketika ia berkompetisi diajang Miss Universe saat itu media tanah air memberitakan foto-foto mesra Elvira bersama ketua KPK Abraham Samad yang tersebar luas di Internet. Seperti yang dikutip dari KapanLagi.com foto-foto tersebut dikabarkan tersebar luas di internet dengan isi dari foto tersebut adalah Elvira dan Abraham Samad yang sedang bermesraan. Kedua nya pun mengakui bahwa foto tersebut adalah rekayasa dan hal itu dibenarkan oleh pakar telematika. 
Namun dengan adanya berita ini Elvira mengakui diri nya sangat terganggu ketika sedang focus mengikuti ajang Miss Universe di Amerika Serikat saat itu. Elvira juga sempat sedih dengan adanya berita ini dapat mencoreng nama baik keluarga nya terlebih lagi dapat menimbulkan persepsi miring masyarakat akan dirinya dan Puteri Indonesia. Sebagai seorang Puteri Indonesia tentu hal tersebut akan menimbulkan persepsi tersendiri dimasyarakat.

Menurut Jalaludin Rakhmat (2007: 51) pengertian persepsi adalah pengamatan tentang objek, peristiwa atau hubungan-hubungan yang diperoleh dengan menyimpulkan informasi dan menafsirkan pesan yang diterimanya. Dari definisi diatas dalam hal ini dapat kita kaitkan bahwa objek peristiwa adalah Event Puteri Indonesia yang menghasilkan para pemenang yang kemudian akan menjadi wakil wanita Indonesia ke tingkat Internasional. Disisi lain Sugihartono, dkk (2007: 8) menjabarkan pengertian persepsi adalah sebagai kemampuan otak dalam menerjemahkan stimulus atau proses untuk menerjemahkan stimulus yang masuk ke dalam alat indera manusia. Persepsi manusia terdapat perbedaan sudut pandang dalam penginderaan. Ada yang mempersepsikan sesuatu itu baik atau persepsi yang positif maupun persepsi negatif yang akan mempengaruhi tindakan manusia yang tampak atau nyata. Berdasarkan uraian diatas maka peneliti tertarik untuk mengetahui adakah pengaruh antara Event Puteri Indonesia dan Elvira Devinamira Terhadap Persepsi Mayarakat atas Wanita Indonesia?

Agar permasalahan yang hendak diteliti tidak mengalami perluasan dan supaya peneliti dapat mendalami maka diperlukan suatu pembatasan masalah. Oleh karena itu, diperlukan penyusunan masalah secara teratur dan sistematis. Maka rumusan masalah dalam penelitan ini adalah:

1. Apakah Event Puteri Indonesia dan Elvira Devinamira dapat berpengaruh pada persepsi masyarakat atas wanita Indonesia?

2. Seberapa besar pengaruh persepsi masyarakat atas wanita Indonesia memalui Event Puteri Indonesia?

\section{METODE PENELITIAN}

Penelitian ini didasarkan pada paradigma positivism. Paradigma positivism ini menerapkan penelitian kuantitatif, yang didasrakan pada hypo deductive method yaitu suatu metode dalam penelitian yang melibatkan pengujian hipotesis yang dideduksi dari hipotesis lain yang tingkat abstraksinya atau perumusan konseptualnya lebih tinggi. Penelitian kuantitatif bertujuan menentukan hubungan antara satu hal (variable dependen atau variable terikat) dalam bentuk angka dari suatu populasi (Hopkins, 2008).

Terdapat dua jenis data dalam penelitian ini yaitu data primer dan data sekunder. Teknik pengumpulan data yang dipakai dalam penelitian ini adalah dengan menyebarkan kuesioner kepada responden dengan pertanyaan - pertanyaan yang telah disusun sebelumnya. Jawaban yang diperoleh pada kuisioner ini diukur dengan skala likert.

Data primer dalam penelitian ini adalah individu, yaitu melalui penyebaran kuesioner kepada Follower Instagram akun @ Indopageants yang pernah menonton, membaca ataupun melihat informasi mengenai event Puteri Indonesia dan Elvira Devinamira. Data sekunder dalam penelitian ini menggunakan data yang sudah dipublikasi, yaitu melalui internet, buku, jurnal, dan surat kabar.

Populasi dalam penelitian ini adalah Follower Instagram akun @Indopageants yang pernah menonton, membaca ataupun melihat informasi mengenai event Puteri Indonesia dan Elvira Devinamira, dimana akun @Indopageants ini memiliki follower sebanyak lebih dari 100.000 followers. Sampel dalam penelitian ini adalah sebagian follower akun Instagram @Indopageants yang pernah menonton, membaca ataupun melihat informasi mengenai event Puteri Indonesia dan Elvira Devinamira.

\section{HASIL DAN PEMBAHASAN}

\section{Profil Elvira Devinamira}

Elvira Devinamira adalah pemenang Puteri Indonesia 2014 yang berasal dari provinsi Jawa Timur. Elvira berhasil mengalahkan 37 wanita dari 34 provinsi di Indonesia dan menjadi wanita ke 2 yang dinobatkan gelar Puteri Indonesia dari provinsi Jawa Timur pada tanggal 29 Januari 2014 di JCC Jakarta. Elvira lahir di Surabaya pada tanggal 28 Juni 1993 dan saat ini tercatat sebagai mahasiswi Fakultas Hukum di Universitas Airlangga. Sebelum menjadi Puteri Indonesia, Elvira menjalani profesi sebagai seorang peragawati profesional.

\section{Uji Validitas dan Reliabilitas Instrumen}

Sebelum melakukan analisis pengaruh event Puteri Indonesia dan Elvira Devinamira terhadap persepsi masyarakat atas wanita Indonesia, peneliti melakukan uji validitas terlebih dahulu melalui 
pernyataan-pernyataan dalam kuesioner dengan menyebar sampel sebanyak 30 responden.

Dengan melakukan penyebaran kuesioner berjumlah responden sebanyak 30 , maka nilai $r$ table dengan batas toleransi error sebesar $10 \% \quad(0,1)$ untuk $\mathrm{N}=30$ (df 30-2=28) adalah $=0,3061$. Dapat disimpulkan jika $r$ hitung lebih besar dibanding $r$ tabel maka pernyataan tersebut dinyatakan valid.

Data yang reliabel adalah data yang jika digunakan beberapa kali untuk mengukur objek yang sama, akan menghasilkan data yang sama (Sugiyono, 2010, p. 121). Reliabel dalam variabel dapat dikatakan baik jika nilai Cronbach's Alpha $>$ dari 0,60.

\section{Variabel X1 (Event Puteri Indonesia)}

Dari hasil penelitian ditemukan bahwa responden menilai Finalis Puteri Indonesia adalah wanita yang berpendidikan dan berkelakuan baik. Hal ini sesuai dengan tujuan dari Yayasan Puteri Indoenesia pada point brain yaitu membentuk Puteri yang memiliki Intelegensia, kecerdasan, ilmu pengetahuan \& mandiri. Finalis Puteri Indonesia adalah wanita penduduk asli dari provinsi yang diwakilkan. Data tersebut menyatakan bahwa finalis Puteri Indonesia adalah harus penduduk asli dari setiap provinsi yang mereka wakilkan. Jakarta adalah tempat yang dinilai tepat untuk karantina Puteri Indonesia. Hal ini mengacu pada salah satu indikator event yaitu tempat, yang dapat menentukan kesuksesan sebuah event. Kemudian pada saat malam final Puteri Indonesia, penyelenggara mengundang duta besar dari negara lain untuk hadir. Hal ini dibutuhkan untuk menjalin hubungan baik antara Indonesia dengan negara tentangga lainnya yang akan memberikan menfaat positif bagi Indonesia.

Kemudian dalam gelaran event Puteri Indonesia, penyelenggara mengundang para aktivis wanita yang aktif dikomunitas pemberdayaan wanita Indonesia untuk hadir di malam final Puteri Indonesia. Hal ini merupakan suatu tindakan yang dapat menginspirasi banyak wanita Indonesia untuk berkarya dan menjadi sosok yang bermanfaat di masyarakat. Malam final Puteri Indonesia disiarkan secara langsung atau live yang dapat disaksikan oleh semua orang di Indonesia. Hal ini merupakan suatu perwujudan dari kompetisi tingkat nasional dimana setiap provinsi di Indonesia memiliki wakilnya masing-masing.

Tata panggung malam final Puteri Indonesia menyuguhkan kekayaan budaya asli Indonesia. Dari awal acara final Puteri Indonesia hingga akhir selalu menampilkan ornamen-ornamen Indonesia dalam setiap sudut panggungnya. Hal ini merupakan contoh nyata bahwa YPI menampilkan acara yang dapat mempromosikan kebudayaan Indonesia.

\section{Variabel X2 (Elvira Devinamira)}

Dari hasil penelitian ditemukan bahwa responden menilai Elvira Devinamira adalah pemenang Puteri Indonesia yang berwawasan luas, sosok yang elegan, cerdas dan kharismatik. Kemudian setelah dirinya menjabat sebagai Puteri Indonesia, Elvira dinilai menjadi sosok inspirator yang baik bagi wanita Indonesia dan sosok panutan di masyarakat.

Selain itu kemampuan berbicara didepan umum yang dimiliki oleh Elvira sangatlah baik dan dapat mempengaruhi masyarakat. Elvira berbicara di depan umum dengan mencerminkan pribadi yang anggun dan ramah. Responden juga setuju bahwa tidak hanya ramah, seorang Puteri Indonesia juga harus memiliki sifat disiplin dan bertanggung jawab. Prestasi Best National Costume yang diraih oleh Elvira membuat Indonesia dikenal sebagai negara yang kaya akan budaya.

Elvira adalah.

Variabel Y (Persepsi Masyarakat Atas Wanita Indonesia)

Dari hasil penelitian ditemukan bahwa responden setuju setelah melihat Pemenang Puteri Indonesia, mereka memiliki persepsi yang baik atas wanita Indonesia. Hal itu juga sejalan pada saat mendengar gaya bicara Puteri Indonesia, mereka berpendapat bahwa wanita Indonesia adalah sosok yang dapat menjadi panutan di masyarakat. Selain itu responden juga setuju dengan pernyataan bahwa mengikuti ajang Puteri Indonesia adalah salah bentuk kecintaan terhadap Indonesia. Kemudian dengan mengikuti ajang Miss Universe, membuat wanita Indonesia dapat mengukir berprestasi di tingkat Internasional. Dimana pariwisata dan budaya Indonesia dapat dipresentasikan dengan baik oleh pemenang Puteri Indonesia di tingkat Internasional.

\section{Pembahasan}

Event Puteri Indonesia adalah ajang kontes kecantikan yang rutin diadakan setiap tahun oleh Yayasan Puteri Indonesia dan dibawahi langsung oleh perusahaan kosmetik Indonesia PT. Mustika Ratu, Tbk. Ajang pemilihan ini telah diadakan sejak tahun 1992 hingga sekarang, dimana sampai dengan saat ini Puteri Indonesia menjadi ajang kontes kecantikan bergengsi bagi para wanita di Indonesia untuk berprestasi di tingkat Nasional dan Internasional.

Penelitian ini terfokus pada Event Puteri Indonesia dengan berbagai dimensi-dimensi seperti 
keunikan, interaksi personal, perishability, intangibility, dan suasana. Kemudian Elvira Devinamira dengan dimensi initial credibility, derivied credibility, dan terminal credibility. Persepsi Masyarakat atas wanita Indonesia dengan dimensi sensasi, atensi dan interpretasi. Teori-teori yang digunakan pada penelitian ini mencakup Source Credibility Theory, konsep Event, dan konsep Persepsi. Untuk metodologi penelitian yang digunakan pada penelitian ini yaitu metode penelitian kuantitatif dengan teknik analisis korelasi, regresi populasi, sampel, teknik pengumpulan data, teknik analisis data, dan waktu hingga tempat penelitian dilaksanakan.

Berdasarkan hasil penelitian telah diketahui bahwa korelasi antara Event Puteri Indonesia dan Elvira Devinamira dengan Persepsi Masyarakat atas wanita Indonesia adalah kuat, yaitu sebesar 0.731 . Kemudian pada hasil analisis regresi menunjukkan bahwa Event Puteri Indonesia dan Elvira Devinamira memiliki hubungan sebesar 0.530 atau $53.0 \%$ dengan Persepsi Masyarakat atas wanita Indonesia. Melihat hal tersebut dapat disimpulan bahwa hubungan Event Puteri Indonesia dan Elvira Devinamira dengan Persepsi Masyarakat atas wanita Indonesia cukup besar, namun terdapat $47.0 \%$ faktor lain yang tidak dijelaskan pada penelitian ini.

Selain itu tedapat 3 pernyataan yang mendapatkan presentase responden tertinggi pada kuesioner yakni sebanyak $97 \%$ responden yang setuju dengan pernyataan tersebut. Pernyataan nya adalah:

1. Tidak hanya ramah, seorang Puteri Indonesia juga harus memiliki sifat disiplin dan bertanggung jawab.

2. Puteri Indonesia dapat menjadi duta bangsa dan mempromosikan segala aspek dari Indonesia ke tingkat Internasional.

3. Cara berfikir wanita Indonesia mencerminkan pribadi yang cerdas dan berbudaya.

Dari hasil yang didapatkan, menunjukkan 96 respoden setuju bahwa Puteri Indonesia tidak hanya dibekali ilmu berbicara didepan umum, namun juga dengan materi kepribadian, intelektual, budaya, pariwisata, dan bahaya narkoba. Hal tersebut dibutuhkan karena sesuai dengan tujuan dari Yayasan Puteri Indonesia yaitu, membentuk tokoh remaja puteri yang dapat menjadi panutan dan tauladan serta pendorong kemajuan wanita dalam berbagai bidang yang berdasarkan pada Beauty, Brain, and Behaviour. Selain itu, diharapkan para kontestan Puteri Indonesia dapat mencerminkan sikap tersebut dan juga dapat menajdi duta bangsa ke tingkat Internasional. Selain itu Yayasan Puteri Indonesia juga dapat menciptakan generasi remaja Puteri yang memberikan dampak positif ke masyarakat Indonesia dan mencitrakan pribadi wanita Indonesia yang sesungguhnya.

Dalam penelitian ini juga terdapat pernyataan yang masih pro dan kontra terhadap pemenang Puteri Indonesia ketika mereka membawa nama Indonesia di ajang bergengsi Miss Universe yaitu, pakaian bikini pada sesi swimsuit tidak cocok untuk digunakan oleh pemenang Puteri Indonesia saat berkompetisi di Miss Universe. Terdapat sebanyak 73 responden yang setuju dengan pernyataan ini, namun tidak dapat dipungkiri bahwa seluruh kontestan Miss Universe termasuk Puteri Indonesia harus menggunakan bikini karena tergolong syarat penilaian semasa karantina dan juga di malam final. Sejak tahun 2005 saat Artika Saridevi mewakili Indonesia di ajang Miss Universe, hal ini mendapat kecaman dari beberapa lapisan masyarakat baik dimedia cetak maupun elektronik karena bikini dinilai tidak sesuai dengan budaya bangsa Indonesia (Mukie, 2016).

\section{KESIMPULAN}

Kesimpulan sementara yang kami ambil dari penelitian ini adalah terdapat pengaruh positif sebesar 50,7\% antara Event Puteri Indonesia dengan Elvira Devinamira terhadap persepsi masyarakat atas wanita Indonesia secara signifikan, dan memang hampir dapat dinyatakan bahwa wanita Indonesia yang mengikuti kontes Puteri Indonesia adalah wanita yang berkelakuan baik dan juga berdasarkan persepsi masyarakat terhadap Event Putri Indonesia dan Elvira Devinamira dengan wanita Indonesia,telah dilakukan studi Eksplanatif pada follower Instagram @ Indopageants oleh peneliti, terdapat beberapa hasil yang dapat disimpulkan:

a. Terdapat pengaruh Event Puteri Indonesia dan Elvira Devinamira terhadap Persepsi Masyarakat atas wanita Indonesia. Hasil menunjukkan terdapat hubungan yang signifikan antara variable X1, X2 dan Y. Hal ini dapat terlihat dari nilai Sig. (1-tailed) yang menunjukkan angka 0.000 , dimana angka ini lebih kecil dari $0.05(0.00<0.05)$. Selain itu terdapat nilai koefisien korelasi sebesar 0.731. Dari angka ini dapat diinterpretasikan tingkat hubungan antara ketiga variabel tersebut termasuk dalam kategori kuat.

b. Terdapat pengaruh parsial dari variabel Event Puteri Indonesia terhadap Persepsi Masyarakat atas wanita Indonesia yaitu sebesar 0.736, dimana pengaruh ini lebih besar dibandingkan pengaruh parsial dari variabel Elvira Devinamira terhadap Persepsi Masyarakat atas wanita Indonesia yaitu sebesar 0.617. Terdapat pula pengaruh simultan 
dari variabel Event Puteri Indonesia dan Elvira Devinamira terhadap Persepsi Masyarakat atas wanita Indonesia yaitu sebesar 0.818, yang lebih besar dibandingkan pengaruh secara parsial.

Karena Event Putri Indonesia merupakaN acara repetitive tahunan jadi memang bisa dipastikan pengaruhnya besar di mata masyarakat sehingga pasti menimbulkan respon yang berbeda dari tiap pihak, sehingga tujuan penelitian ini sendiri melihat reaksi yang timbul tersebut melalui media sosial, sehingga kedepannya secara umum komite yang bersangkutan dapat meningkatkan kualitas acara dan bisa memisahkan mana yang merupakan kritik dan feedback dari masyarakat dapat diimplementasikan agar Event ini dapat terus berkembang dan dapat diikuti oleh masyarakat, mungkin diubah secara konten acara yang tetap menarik penonton dan memberikan banyak sponsor akan tetapi dapat tetap mengedukasi dan menjadi sarana untuk bermimpi juga mengabulkan mimpi banyak wanita Indonesia diluar Indonesia.

Terdapat beberapa saran akademis yang dapat diberikan oleh peneliti, yakni dibutuhkan penelitian lebih lanjut dengan menggunakan metode penelitian yang lain dengan obyek penelitian yang sama, sehingga hasil penelitian dapat lebih akurat. Peneliti selanjutnya sebaiknya dapat mengembangkan penelitian dengan menambahkan beberpa teori yang berhubungan yang tidak terdapat pada penelitian ini.Dari sudut pandang teori yang berbeda dengan porsi isi kompisisi permasalahan yang sama dapat membantu memberikan perspektif yang baru dan berbeda terhadap hasil dari penelitian ini.Juga bisa memberikan saran lain yang mungkin bisa lebih membantu semua acara dengan template yang sejenis agar dan lebih improve dalam merepresentasikan peserta mereka yang akan dipublish di masyarakat agar dapat menjadi contoh yang baik dikarenakan masyarakat internet Indonesia yang mudah terprovokasi dan tersulut emosi dan mudah dalam merundung orang yang mereka anggap salah di media sosial secara masif dan terus menerus.

Saran praktis dari peneliti terhadap Event Puteri Indonesia adalah bahwa kedepannya event ini dapat memberikan dampak yang baik terhadap wanita Indonesia, karena mengacu pada hasil penelitian bahwa masyarakat memberikan persepsi positif terhadap event kontes kecantikan tersebut sehingga terus kedepannya dapat memberikan hal-hal baik yang dapat dicontoh oleh masyarakat luas terutama wanita Indonesia agar mereka dapat terus berkembang serta menjaga dan meningkatkan kecantikan mereka dari luar atau dalam dan menjadi lahan besar untuk bermimpi setinggi-tingginya dan terus menerus belajar dalam segala bidang karena Event ini menunjukkan tidak hanya kecantikan fisik yang dilihat akan tetapi juga tutur kata dan cara pemikiran mereka pun menjadi tolak ukur untuk mereka bersaing dalam kompetisi ini, sehingga dapat menjadi salah satu kompetisi yang mengeluarkan aura wanita Indonesia sekaligus memberi unjuk pada dunia kualitas wanita Indonesia itu sendiri.

\section{REFERENSI}

Arifin, Z. (2012). Penelitian Pendidikan Metode dan Paradigma Baru. Bandung: Rosdakarya..

Azwar, S. (2011). Sikap Manusia: Teori dan Pengukurannya. Jakarta: Pustaka Pelajar.

Azwar, S. (2003). Reliabilitas dan Validitas. Edisi 3. Yogyakarta: Pustaka Pelajar Offset.

Any, N. (2009). Management Event. Bandung: Alfabeta.

Antar, V. (2009). Manajemen Kampanye: Panduan Teoritis dan Praktis dalam Mengefektifkan kampanye komunikasi. Bandung: Simbiosa Rekatama Media.

Bambang, P., \& Jannah, L. M. (2005). Metode Penelitian Kuantitatif: teori dan aplikasi. Jakarta: RajaGrafindo Persada.

Butterick, K. (2012). Pengantar Public Relations Teori dan Praktik. Depok: PT Rajagrafindo Persada.

Bungin, M. B. (2005). Metodologi Penelitian Kuantitatif: Komunikasi, Ekonomi, Kebijakan Publik, dan Ilmu Sosial Lainnya. Jakarta: Kencana.

Devito, A. J. 2011. Komunikasi Antarmanusia. Tanggerang Selatan: Karisma Publishing Group.

Effendy, O. U. (2003). Ilmu Komunikasi Teori dan Praktek. Bandung: PT Remaja Rosdakarya.

Faulina, E. S. (2011). Professional Public Relations. Medan: USU Press.

Ghozali, I. (2005). Aplikasi Analisis Multivariate dengan SPSS. Semarang: Badan Penerbit UNDIP.

Hafidz, I. N. (2007). Mengulik Bisnis Event Organizer, Yogyakarta: Gava Media.

Haryadi S, dan Winda J. (2011). SPSS vs LISREL sebuah pengantar Aplikasi untuk Riset. Jakarta: Salemba Empat. 
Hopkins, W.G. (2008). Quantitative Research Design. Diambil kembali dari Perfective or Research Resources.

Hovland, C.L., Janis, I. L., \& Kelly, H. H. (1953). Communication and Persuasions: Psychological studies of opinion change. New Heaven, Conn: Yale University Press.

Hovland,C. L. (2007). Definisi Komunikasi. Jakarta: PT.RajaGrafindo Persada.

Husaini U, dan Akbar P. S. (2008). Pengantar Statistika. Jakarta: PT. Bumi Aksara.

Jalaludin R. (2005) Psikologi Komunikasi, Edisi revisi. Bandung: Remaja Rosdakarya.

John, P. S. (2003). Public Relations. Yogyakarta: Graha Ilmu.

Judy T.C.W. (Autumn 1997). Loveliest Daughter of Our Ancient Cathay!": Representations of Ethnic and Gender Identity in the Miss Chinatown U.S.A. Beauty Pageant Journal of Social History Vol. 31, No. 1 pp. 5-31: Oxford University Press Retrieved from Stable URL: http://www.jstor.org/stable/3789855.

Kriyantono, R. (2006). Teknik Praktis Riset Komunikasi. Jakarta: Kencana Prenada Media Group

Liberman, A. M. ; Cooper, F. S. and Shankweiler, D. P.; Studdert-K. M. Psychological Review, Vol 74(6), Nov 1967, 431-461. Perception of the speech code. Retrieved from http://dx.doi.org/10.1037/h0020279

Lidia, E. M. (2005). Event Organizer Pameran. Jakarta: PT Indeks Kelompok Gramedia.

Marzuki. (2005). Metodologi Riset. Yogyakarata: Ekonisia.

Matthew C. N. and John E. K. (March 2009). Science Communication,; vol. 30, 3: pp. 328-354., first published on January 8, 2009 Retrieved from http://online.sagepub.com/search?fulltext $=O$ pi nion-

Leader+Campaigns + on + Climate + Change. $\& x$ $=0 \& y=0 \& s r c=h w \&$ andorexactfulltext $=$ and $\& s$ ubmit $=y e s$.

Mulyana, D. (2008). Ilmu Komunikasi Suatu Pengantar. Bandung: Remaja Rosdakarya.

Natoradjo, S. (2011). Event Organizing: Dasar-Dasar Event Management. Jakarta: Gramedia Pustaka Utama.

Pudjiastuti, W. (2010). Special Event: Alternatif Jitu Membidik Pasar. Jakarta: Elex Media Komputerindo.
Sugihartono. (2007). Psikologi Pendidikan. Yogyakarta: UNY Pres.

Sugiyono. (2008). Metode Penelitian Kuantitatif Kualitatif dan $R \& D$. Bandung: Alfa Beta.

Tahir, M. 2011. Pengantar Metodologi Penelitian Pendidikan. Makassar: Universitas Muhammadiyah Makassar.

Wasesa, S. A. (2005). Strategi Public Relations. Jakarta: PT. Gramedia Pustaka. 